\title{
INSECT ENEMIES OF THE CHINCH-BUG
}

By W. P. Furnt, Assistant Entomologist, Urbana, Ill.

While the chinch-bug occupies a very prominent place in the writings of economic entomologists, up to the time of the discovery of its egg parasite, Eumicrosoma benefica Gahan, by McColloch in Kansas in 1913, but very little detailed study had been given to its predaceous or parasitic insect enemies.

Walsh in some of his earlier writings on the chinch-bug says that it is attacked by four species of ladybugs, the most efficient being Hippodamia maculata.

Henry Shimer described in 1865 a new species of Chrysopa ( $C$. illinoiensis) which he found in a cornfield feeding upon chinch-bugs, and reported that one of the larva of this species which he kept in confinement ate a dozen in quick succession. Later he reared Hippodamia maculata from egg to adult by feeding it upon nothing but chinch-bugs.

LeBaron mentions lace wing flies and ladybugs as the only insect enemies of the chinch-bug, but says that chinch-bugs are fewer than usual on hills of corn which have ant-hills at their base.

Thomas states that the chinch-bug is fed upon by Hippodamia maculata.

Riley says that the above mentioned insects feed upon the chinchbug, and that he thinks ants are of some benefit in reducing its numbers.

Forbes found from an examination of the stomach contents of a number of the common ground beetles found in fields infested by the chinch-bug that about a fifth of the food of Agonoderus pallipes was derived from chinch-bugs.

Webster says that the chinch-bug has no insect enemies of importance; he mentions that it is infested by a species of Mermis or hair snake, and that its worst insect enemies are to be found in its near relatives, the insidious flower bug (Triphleps insidiosus) and Milyas cinctus.

Headlee and McColloch report that besides the above mentioned insects, they have occasionally seen the false chinch-bug, Nysius angustatus, feeding upon the chinch-bug, and have repeatedly found three species of ground beetles, Harpalus compar, Evarthrus sodalis, and Anisodactylus harpaloides eating it. They also saw a cricket feeding on chinch-bugs and two of the small ants commonly found in grain fields, Solenopsis molesta and Monomorium minimum, carrying chinchbug eggs and dead adults. 
A few other insects have occasionally been found to feed on the chinch-bug but it has been generally supposed that predaceous insects are only a very slight check on its increase.

During the recent outbreak of this insect in Illinois (1909-1915) a number of observations on its predaceous enemies were made by the writer while conducting experiments on methods of chinch-bug control. In the summer of 1915 a number of insectary experiments were made to learn just how many chinch-bugs the more abundant of these predaceous insects would eat, and how common they were in the field. Those most commonly found feeding on the chinch-bug throughout the infested area in Illinois were adults and nymphs of the damsel bug, Reduviolus ferus, larvæ of Chrysopa and Hemerobius, adults of the small ground beetles, Blechrus glabratus and B. pusio, nymphs and adults of Pagasa fusca, larvæ of several species of Coccinellidæ, and nymphs and adults of the common flower bug, Triphelps insidiosus. The ground beetles most common in infested fields were not found to feed on chinch-bugs to any extent. Casnonia pennsylvanica ate small numbers of them and Agonoderus pallipes ate dead bugs and molt skins. Ants were never observed to attack living chinch-bugs in the fields although they would do so when the bugs approached an ant nest. Several of the species common in cornfields were noticed carrying dead bugs. Cincindelid adults were seen to eat small numbers of chinch-bugs along barrier lines.

The following notes give the detailed results of the studies of the above mentioned insects. In these experiments single specimens of the predaceous insects to be tested were placed in clean vials with a known number of chinch-bugs of known stages of growth. A few sections of foxtail grass were also placed in the vials as food for the chinch-bugs, and the vials stopped with cotton. These vials were examined daily and fresh food for the chinch-bugs added and fresh bugs as needed. By the use of check vials in which only chinch-bugs were confined, it was found that they could be kept in a normal state of growth in this way, several lots being carried through from egg to adult.

Chrysopa oculata and C. rufilabris. Chrysopa larvæ were abundant in all fields of grain infested by the chinch-bug. They were often seen feeding on chinch-bug nymphs especially in cornfields where they would be found behind the boots of the lower leaves where the chinchbugs were most abundant. In a number of cases chrysopa larvæ were seen to suck from three to five chinch-bugs in the course of ten minutes. The insectary experiments were first started with chrysopa larvæ collected in the field in different stages of growth, but were later carried on with larvæ hatched from eggs in the insectary. 
These experiments showed that where first and second instar chinchbugs were offered as food, the chrysopa larvæ ate from four to six per day and that about 100 of these nymphs would be required for the chrysopa to complete its growth from egg to adult. Counts made in cornfields after the first of August showed that chrysopa larvæ would average about six per hill of corn in fields where chinch-bugs were abundant.

The damsel bug, Reduviolus ferus. During the past chinch-bug infestation this insect has been noted as probably the most common of any of the insects feeding upon chinch-bugs in all situations.

Insectary experiments with this species showed that both nymphs and adults fed readily on chinch-bugs, that they seemed to prefer chinch-bug nymphs in the third or fourth instar and occasionally fed on adults. An average of about two chinch-bugs per day were eaten where the observation extended over a period of two to three weeks.

Blechrus glabratus. This small, very active beetle apparently feeds only on chinch-bugs in the first and second instars, its size making it very difficult for it to overpower the larger bugs. In the insectary experiments one of these beetles ate eighty-eight chinch-bugs in twentysix days. In another case eighteen first instar chinch-bugs were eaten in twenty-four hours.

These beetles can be found in the adult stage in all grain fields after the middle of June. They have been taken in fairly large numbers in the hibernating quarters of chinch-bug, especially in the bases of the large clump farming grasses.

Another fairly efficient chinch-bug predator, although not occurring in grain fields in very large numbers, is the Nabid, Pagasa fusca. All stages of this insect from small nymphs to adults have frequently been seen in infested fields feeding upon the chinch-bug. In the insectary experiments with this insect all specimens used died during the molting process although in some cascs one or two molts were successfully completed. For this reason no complete records of the number of chinch-bugs eaten by individuals of this species was obtained. This insect seems to prefer the later stages of the chinch-bug and has been seen a number of times in the fields feeding upon adults.

In the insectary experiments this species ate from one to two chinchbugs per day for a period of from five to thirty-six days.

During the hatching period of the second brood of chinch-bugs one of the most efficient of their enemies is the predatory flower bug, Triphleps insidiosus. This insect has been seen in small numbers in infested fields of small grain but has been found in abundance in the cornfields during late July, August and September. The small size of this insect makes it impossible for it to feed upon any but first 
and second instar chinch-bugs; both nymphs and adults have been seen a number of times in the field feeding on the early stages of the chinch-bug. In cornfields it would sometimes be found to average five and six to the stalk of corn over the entire field.

The insectary experiments with this species showed that about twelve first instar chinch-bugs were required for the flower bug to complete its growth to adult, and that these were taken at the rate of a little less than one per day. Their appetite for chinch-bugs did not decrease when the adult stage was reached as they still continued to feed at about the same rate as the nymphs.

Only two of the ground beetles common in the chinch-bug infested field could be induced to feed upon chinch-bugs in the course of the insectary experiments. Casnonia pennsylvanica has been seen feeding upon chinch-bugs in the stubble fields but only in one or two cases during the past five years. The results of the insectary experiments do not show that this beetle would be of much importance in reducing the number of chinch-bugs in an infested field. One specimen ate ten chinch-bugs in forty-eight days, another eight during the same period, while a third only ate five in forty-two days. Only chinchbugs in the later stage of growth were eaten.

The small striped ground beetle, Agonoderus pallipes, is very common in all grain fields in the central and southern part of Illinois but was never seen to attack living chinch-bugs in the field. In the insectary experiments with this species one beetle under observation for fiftyfive days ate seven dead chinch-bugs but would not attack living bugs although confined with them for this entire period. Another specimen of the same insect kept under the same conditions for eighteen days ate one dead chinch-bug and one cast molt skin.

In the field larvæ of Coccinellids were frequently seen to feed upon chinch-bugs. Several attempts in the insectary to get the number of chinch-bugs eaten by the different species of these larvæ were without definite results. The Coccinellids were never contented in any of the several types of cages used and spent nearly the entire time trying to get out, all dying within a week. A few chinch-bugs were eaten by them however.

Experiments with a few other species of ground beetles found in the chinch-bug infested fields did not show that these insects fed upon chinch-bugs.

To try and get a definite idea of the abundance of the chinch-bug predators in the fields counts were made of the number of these insects occurring in a measured square yard of stubble in a number of fields in central Illinois during July. On the average enough predaceous insects of the above species were found to eat eleven chinch-bugs per 
day per square yard, or about two million per day for a forty acre field; this estimate being based on the results of the above insectary feeding experiments where only chinch-bugs were offered as food.

In the above counts it should be kept in mind that certainly not over one-half and probably not over one-third of the Blechrus present were counted. This insect is very active and seeks to hide on the least disturbance and its small size renders it very hard to see. The same is also true of Pagasa fusca. While in this case the insect is somewhat larger it is even more easily alarmed. Even the numbers of predators shown in the above counts however would easily account for ten chinch-bugs per square yard per day.

Fifteen bunches of grass in a moderately infested cornfield were carefully examined and yielded four hundred fifty-four chinch-bugs, two ladybugs, three Reduviolus, five predatory flower bugs and five Chrysopa larvæ, or enough predatory species to account for at least twenty chinch-bugs per day.

During the entire month of August, 1915, examinations made in cornfields in west central Illinois showed the predatory flower bug often averaging five to six per stalk of corn and Chrysopa larvæ, nymphs and adults of Reduviolus, Pagasa fusca and adults of Blechrus abundant in all chinch-bug infested fields.

It seems probable from the abundance of these insects in the fields and the numbers of chinch-bugs known to be eaten by them that when after a period of abundance the chinch-bug increase is checked by adverse weather conditions, that these predatory species together with the egg parasite may keep them from causing damage for a number of years. During the season of 1917 with a wide area in Illinois dangerously infested with chinch-bugs no marked damage has been done partly because of the abundance of these predatory species in the fields. Reduviolus and Pagasa fusca have been unusually abundant in chinchbug infested fields during the past summer. 